\title{
Macrolide Resistance in Streptococcus pneumoniae in Hong Kong
}

\author{
MARGARET IP, ${ }^{1 *}$ DONALD J. LYON,${ }^{1}$ RAYMOND W. H. YUNG,${ }^{2}$ COLIN CHAN,${ }^{1}$ AND \\ AUGUSTINE F. B. CHENG ${ }^{1}$
}

Department of Microbiology, The Chinese University of Hong Kong, Prince of Wales Hospital, Shatin, ${ }^{1}$ and Pamela Youde Nethersole Eastern Hospital, ${ }^{2}$ Hong Kong, China

Received 17 August 2000/Returned for modification 31 January 2001/Accepted 15 February 2001

\begin{abstract}
Erythromycin resistance rates among penicillin-susceptible Streptococcus pneumoniae were 38 and $92 \%$ among penicillin-intermediate and -resistant $S$. pneumoniae isolates from Hong Kong, respectively, and $27 \%$ (43 of 158) of the isolates showed the $\mathrm{MLS}_{\mathrm{B}}$ phenotype, and the majority carried the ermB gene; $73 \%$ (115 of 158) displayed the $M$ phenotype, and all possessed the mef gene. The $M_{L S}$ phenotype was predominant in penicillin-susceptible, macrolide-resistant isolates and in penicillin-nonsusceptible isolates of serotype 6B, whilst the $M$ phenotype was predominant in penicillin-intermediate or -resistant isolates belonging to serotype 23F or 19F. Extensive spread of clones of drug-resistant pneumococci has led to the widespread presence of macrolide resistance in $S$. pneumoniae in Hong Kong.
\end{abstract}

Macrolide resistance among Streptococcus pneumoniae has increased in many countries, such as the United States $(2,3)$ and United Kingdom (4). Two principal mechanisms of macrolide resistance have been described (10); target modification is mediated by an rRNA erythromycin resistance methylase and coded by the ermB (ermAM) gene. These organisms express the $\mathrm{MLS}_{\mathrm{B}}$ phenotype and show broad cross-resistance to macrolides, lincosamides, and streptogramin B antibiotics. The $\mathrm{M}$ phenotype involves an active efflux pump, which removes only 14-membered and 15-membered macrolides from the bacterial cell (14). The determinant was identified to be the mef (mefE) gene (15). Isolates showing the M phenotype are susceptible to clindamycin and streptogramin B. In 1999, two further mechanisms were described, one mediated by alterations in the L4 ribosomal protein, and another due to mutation in the $23 \mathrm{~S}$ rRNA (15a). The incidence of erythromycin resistance in pneumococci at the Prince of Wales Hospital, Hong Kong, has risen from 22\% in 1993 to $42 \%$ in 1997 (6). The likely explanation is the dissemination of a few clones of multidrug-resistant $S$. pneumoniae in the Hong Kong population as previously described (5). The objective of the present study was to investigate the prevalence and distribution of the macrolide resistance determinants in isolates of $S$. pneumoniae in Hong Kong. In addition, the relationships between these determinants, penicillin susceptibility, and their serotypes were also determined.

A total of 197 strains of $S$. pneumoniae isolated at the Prince of Wales Hospital and Pamela Youde Nethersole Eastern Hospital, Hong Kong, from 1994 to 1998 were studied. Approximately $25 \%$ were invasive isolates from blood and cerebrospinal fluid, and the remainder were from sputum which had reduced penicillin susceptibility by the $1-\mu \mathrm{g}$ oxacillin disk method. The two hospitals are located in the northern and

\footnotetext{
* Corresponding author. Mailing address: Dept. of Microbiology, Chinese University of Hong Kong, Prince of Wales Hospital, Shatin, New Territories, Hong Kong, China. Phone: (852) 2632 2306. Fax: (852) 2647 3227. E-mail: margaretip@cuhk.edu.hk.
}

southern parts of Hong Kong, and the isolates were thus deemed to be representative of strains from patients with pneumococcal infections requiring hospital admissions in Hong Kong. The penicillin-intermediate or -resistant isolates had previously been well characterized by molecular typing using $p b p$ gene profiles and pulsed-field gel electrophoresis (PFGE) (5).

MICs of penicillin, erythromycin, clarithromycin, and clindamycin were determined by the agar dilution method (8). Inocula of $10^{4} \mathrm{CFU} /$ spot were incubated at $35^{\circ} \mathrm{C}$ for $18 \mathrm{~h}$ on Mueller-Hinton agar supplemented with 5\% defibrinated horse blood. S. pneumoniae ATCC 6315 and 49619 were included as controls. Inducible resistance to clindamycin was detected by the method previously described (11). Conserved primer sets were chosen to amplify a 640-bp fragment of the erm methylase genes as follows: erm A, 5' -TCTAAAAAGCAT GTAAAAGAA-3' and 5'-CTTCGATAGTTTATTAATATT AGT-3'; ermB, 5'-GAAAAGGGTACTCAACCAAATA-3' and $5^{\prime}$-AGTAACGGTACTTAAATTGTTTAC-3'; and erm $C$, 5'-TCAAAACATAATATAGATAAA-3' and 5'-GCTAATA TTGTTTAAATCGTCAAT-3'. A 1.2-kb fragment of the mef gene in $S$. pneumoniae was amplified using primer pair 5'-GA AAAATACAACAATTGGAAAC-3' and 5'-AATCTAATTT TCTAACCTCA- $3^{\prime}$. PCRs were performed on the OmniGene DNA thermal cycler (Hybaid) using an initial denaturation at $94^{\circ} \mathrm{C}$ for 5 min followed by 35 cycles of amplification at $94^{\circ} \mathrm{C}$ for $30 \mathrm{~s}, 50^{\circ} \mathrm{C}$ for $30 \mathrm{~s}$, and $72^{\circ} \mathrm{C}$ for $90 \mathrm{~s}$. A final elongation step was performed at $72^{\circ} \mathrm{C}$ for a further $7 \mathrm{~min}$. All the strains were serotyped by the chessboard agglutination or the quellung reaction method using Pneumotest antisera (Statens Seruminstitut, Copenhagen, Denmark).

A total of $80 \%$ (158 of 197) of the S. pneumoniae strains were resistant to erythromycin with a MIC of $\geq 1.0 \mu \mathrm{g} / \mathrm{ml}, 27 \%$ (43 of 158) showed an MLS $_{\mathrm{B}}$ phenotype with erythromycin and clindamycin $50 \%$ and $90 \%$ MICs $\left(\mathrm{MIC}_{50}\right.$ and $\left.\mathrm{MIC}_{90}\right)$ of $>64$ $\mu \mathrm{g} / \mathrm{ml} ; 73 \%$ (115 of 158 ) showed resistance to erythromycin alone, with $\mathrm{MIC}_{50}$ and $\mathrm{MIC}_{90}$ of $8.0 \mu \mathrm{g} / \mathrm{ml}$. The MICs of the antibiotics tested for these two groups are shown in Table 1. Of 
TABLE 1. MICs of 197 Hong Kong S. pneumoniae isolates for four antibiotics by macrolide and lincosamide susceptibility phenotypes

\begin{tabular}{|c|c|c|c|}
\hline $\begin{array}{l}\text { Macrolide phenotype } \\
\text { (no. of strains) }\end{array}$ & $\begin{array}{l}\text { MIC range } \\
(\mu \mathrm{g} / \mathrm{ml})\end{array}$ & $\begin{array}{l}\mathrm{MIC}_{50} \\
(\mu \mathrm{g} / \mathrm{ml})\end{array}$ & $\begin{array}{l}\mathrm{MIC}_{90} \\
(\mu \mathrm{g} / \mathrm{ml})\end{array}$ \\
\hline \multicolumn{4}{|l|}{ Penicillin } \\
\hline $\operatorname{MLS}_{\mathrm{B}}(43)$ & $<0.03-2.0$ & 1.0 & 2.0 \\
\hline M (115) & $<0.03-4.0$ & 1.0 & 2.0 \\
\hline S (39) & $<0.03-2.0$ & 0.03 & 1.0 \\
\hline \multicolumn{4}{|l|}{ Erythromycin } \\
\hline $\operatorname{MLS}_{\mathrm{B}}(43)$ & $8.0->64.0$ & $>64.0$ & $>64.0$ \\
\hline M (115) & $1.0-64.0$ & 8.0 & 8.0 \\
\hline S (39) & $0.12-0.25$ & 0.25 & 0.25 \\
\hline \multicolumn{4}{|l|}{ Clarithromycin } \\
\hline $\mathrm{MLS}_{\mathrm{B}}(43)$ & $8.0->64.0$ & $>64.0$ & $>64.0$ \\
\hline M (115) & $1.0-64.0$ & 8.0 & 8.0 \\
\hline S (39) & $0.12-0.25$ & 0.25 & 0.25 \\
\hline \multicolumn{4}{|l|}{ Clindamycin } \\
\hline $\operatorname{MLS}_{\mathrm{B}}(43)$ & $1.0->64.0$ & $>64.0$ & $>64.0$ \\
\hline M (115) & $0.12-0.5$ & 0.25 & 0.25 \\
\hline S (39) & $0.12-0.25$ & 0.25 & 0.25 \\
\hline
\end{tabular}

${ }^{a} \mathrm{MLS}_{\mathrm{B}}$, macrolide and lincosamide resistance phenotype; M, erythromycinresistant, clindamycin-susceptible phenotype; $\mathrm{S}$, erythromycin- and clindamycinsusceptible isolates.

the isolates expressing the $\mathrm{MLS}_{\mathrm{B}}$ phenotype, only the ermB gene was detected in $93 \%$ of the isolates by PCR. Three isolates were repeatedly negative on testing for $\operatorname{erm} A,-B$, or $-C$, and hence perhaps other mechanisms of macrolide resistance exist. All the isolates expressing the M phenotype were positive for the mef gene by PCR. Table 2 shows the serotypes of $S$. pneumoniae in relation to penicillin and macrolide susceptibility. Among the 42 penicillin-susceptible isolates, 16 (38\%) isolates were resistant to erythromycin with a MIC of $\geq 1.0 \mu \mathrm{g} / \mathrm{ml}$, and $62.5 \%$ of the penicillin-susceptible, macrolide-resistant isolates showed the $\mathrm{MLS}_{\mathrm{B}}$ phenotype. However, of the 155 penicillin-intermediate or -resistant isolates examined, 142 (92\%) isolates were resistant to erythromycin, 107 of 142 (75\%) of these belonged to the $\mathrm{M}$ phenotype, whilst the remainder (35 of 142, 25\%) belonged to the $\mathrm{MLS}_{\mathrm{B}}$ phenotype, with a $\mathrm{MLS}_{\mathrm{B}} / \mathrm{M}$ phenotype ratio of 1:3. The $\mathrm{MLS}_{\mathrm{B}}$ phenotype was mainly associated with serotype $6 \mathrm{~B}(P>0.001$, chi square test), whilst the $\mathrm{M}$ phenotype was predominant in isolates expressing serotype $23 \mathrm{~F}$ or $19 \mathrm{~F}$ ( $P>0.001$, chi square test).

The study indicated a high percentage of erythromycin resistance among clinical isolates of $S$. pneumoniae in Hong Kong, with $38 \%$ in penicillin-susceptible pneumococci and $92 \%$ of penicillin-intermediate or -resistant isolates. Our previous study (5) showed that these strains belonging to $19 \mathrm{~F}$ and $23 \mathrm{~F}$ had identical $p b p$ profiles and PFGE fingerprints and belong to clones indistinguishable from that belonging to the Spanish 23F clone. Similarly, isolates belonging to serotype 6B had unique $p b p$ profiles and identical PFGE fingerprints to that of the Spanish $6 \mathrm{~B}$ clone (5). The data further support the hypothesis that the dissemination of particular clones of $S$. pneumoniae of reduced penicillin susceptibility has been responsible for the spread of macrolide resistance determinants in Hong Kong. In Canada and the United States, the M phenotype was prevalent in 55.8 and $71 \%$, respectively, of the macrolide-resistant pneumococci $(3,7)$. In contrast, the $\mathrm{MLS}_{\mathrm{B}}$
TABLE 2. Serotypes of $S$. pneumoniae in relation to penicillin and macrolide susceptibility ${ }^{a}$ (197 isolates)

\begin{tabular}{lrr}
\hline & \multicolumn{2}{c}{$\begin{array}{c}\text { No. of isolates with the following } \\
\text { penicillin susceptibility: }\end{array}$} \\
\cline { 2 - 3 } macrolide phenotype & $\mathrm{S}$ & I or $\mathrm{R}$ \\
\hline $23 \mathrm{~F}$ & 3 & 9 \\
$\mathrm{~S}$ & 3 & 5 \\
$\mathrm{R}_{\mathrm{MLSB}}$ & 2 & 64 \\
$\mathrm{R}_{\mathrm{M}}$ & & \\
$19 \mathrm{~F}$ & 1 & 0 \\
$\mathrm{~S}$ & 0 & 3 \\
$\mathrm{R}_{\mathrm{MLSB}}$ & 0 & 39 \\
$\mathrm{R}_{\mathrm{M}}$ & & 3 \\
$6 \mathrm{~B}$ & & 23 \\
$\mathrm{~S}$ & 1 & 3 \\
$\mathrm{R}_{\mathrm{MLSB}}$ & 0 & \\
$\mathrm{R}_{\mathrm{M}}$ & 2 & 0 \\
14 & & 2 \\
$\mathrm{~S}$ & 0 & 3 \\
$\mathrm{R}_{\mathrm{MLSB}}$ & 3 & 1 \\
$\mathrm{R}_{\mathrm{M}}$ & 2 & 0 \\
Other & & 0 \\
$\mathrm{~S}$ & 21 & \\
$\mathrm{R}_{\mathrm{MLSB}}$ & 4 & \\
$\mathrm{R}_{\mathrm{M}}$ & 0 & \\
Total & 42 & \\
\hline
\end{tabular}

${ }^{a} \mathrm{~S}$, sensitive; I, intermediate; R, resistant; MLSB, macrolide and lincosamide resistance phenotype; $\mathrm{M}$, erythromycin-resistant, clindamycin-susceptible phenotype.

resistance mechanism predominates in European countries, and the mef gene was only found in 1, 5.8, and 9\% among resistant pneumococci in France (P. Angot, M. Vergnaud, and R. Leclerq, Program Abstr. 39th Intersci. Conf. Antimicrob. Agents. Chemother. abstr. 1221, 1999), Italy (9), and Belgium (1) respectively. Macrolide resistance has been reported to be high among pneumococci in Asian countries (13), but the distribution of these macrolide resistance determinants is not known. As in Hong Kong, penicillin- and multidrug-resistant $S$. pneumoniae clones belonging to serotypes 19 and 23 disseminated widely in the last decade in Taiwan (12), Korea (17), and Japan (18), and it is likely that the mef genes are prevalent among the penicillin-resistant pneumococci in these countries too.

The 14- and 15-membered macrolides have poor activity against Hong Kong clinical isolates of $S$. pneumoniae, particularly against penicillin-intermediate or -resistant strains. This study supported the widespread dissemination of the macrolide resistance determinants, particularly the mef gene, which occurred with the spread of penicillin-nonsusceptible pneumococcal clones in Hong Kong.

The work described in this paper was fully supported by grants from the Research Grants Council of the Hong Kong Special Administrative Region (Project Nos. CUHK 4215/97M and 4331/99M).

\section{REFERENCES}

1. Descheemaeker, P., S. Chapelle, C. Lammens, M. Hauchecorne, M. Wijdooghe, P. Vandamme, M. Ieven, and H. Goossens. 2000. Macrolide resistance and erythromycin resistance determinants among Belgian Streptococ- 
cus pyogenes and Streptococcus pneumoniae isolates. J. Antimicrob. Chemother. 45:167-173.

2. Doern, G. V., M. A. Pfaller, K. Kugler, J. Freeman, and R. N. Jones. 1998. Prevalence of antimicrobial resistance among respiratory tract isolates of Streptococcus pneumoniae in North America; 1997 results from the SENTRY antimicrobial surveillance program. Clin. Infect. Dis. 27:764-770.

3. Doern, G. V., A. B. Brueggemann, H. Huynh, E. Wingert, and P. Rhomberg. 1999. Antimicrobial resistance with Streptococcus pneumoniae in the United States, 1997-98. Emerg. Infect. Dis. 5:757-765.

4. Hall, L. M. C., R. A. Whiley, B. Duke, R. C. George, and A. Efstratiou. 1996. Genetic relatedness within and between serotypes of Streptococcus pneumoniae from the United Kingdom: analysis of multilocus enzyme electrophoresis, pulsed-field gel electrophoresis, and antimicrobial resistance patterns. J. Clin. Microbiol. 34:853-859.

5. Ip, M., D. J. Lyon, R. W. H. Yung, C. Chan, and A. F. B. Cheng. 1999. Evidence of clonal dissemination of multidrug-resistant Streptococcus pneumoniae in Hong Kong. J. Clin. Microbiol. 37:2834-2839.

6. Ip, M., D. J. Lyon, A. F. B. Cheng. 2001. Patterns of antibiotic resistance, serotype distribution, and patient demographics of Streptococcus pneumoniae in Hong Kong. Chemotherapy 47:110-116.

7. Johnston, N. J., A. J. De, J. D. Kellner, and D. E. Low. 1998. Prevalence and characterization of the mechanisms of macrolide, lincosamide, and streptogramin resistance in isolates of Streptococcus pneumoniae. Antimicrob. Agents Chemother. 42:2425-2426.

8. National Committee for Clinical Laboratory Standards. 1998. Performance standards for antimicrobial susceptibility testing, 8th informational supplement, M100-S8, 5th ed. National Committee for Clinical Laboratory Standards, Villanova, Pa.

9. Oster, P., A. Zanchi, S. Cresti, M. Lattanzi, F. Montagnani, C. Cellesi, and G. M. Rossolini. 1999. Patterns of macrolide resistance determinants among community-acquired Streptococcus pneumoniae isolates over a 5-year period of decreased macrolide susceptibility rates. Antimicrob. Agents Chemother. 43:2510-2512.

10. Roberts, M. C., J. Sutcliffe, P. Courvalin, L. B. Jensen, J. Rood, and H. Seppala. 1999. Nomenclature for macrolide and macrolide-lincosamide- streptogramin B resistance determinants. Antimicrob. Agents Chemother. 43:2823-2830.

11. Seppala, H., A. Nissinen, Q. Yu, and P. Huovinen. 1993. Three different phenotypes of erythromycin-resistant Streptococcus pyogenes in Finland. J. Antimicrob. Chemother. 32:885-891.

12. Shi, Z. Y., M. C. Enright, P. Wilkinson, D. Griffiths, and B. G. Spratt. 1998. Identification of three major clones of multiply antibiotic-resistant Streptococcus pneumoniae in Taiwanese hospitals by multilocus sequence typing. J. Clin. Microbiol. 36:3514-3519.

13. Song, J. H., N. Y. Lee, S. Ichiyama, R. Yoshida, Y. Hirakata, W. Fu, A. Chongthaleong, N. Aswapokee, C. H. Chiu, M. K. Lalitha, K. Thomas, J. Perera, T. T. Yee, F. Jamai, U. C. Warsa, B. X. Vinh, M. R. Jacobs, P. C. Appelbaum, C. H. Pai, and the ANSORP Study Group. 1999. Spread of drug-resistant Streptococcus pneumoniae in Asian countries: Asian Network for Surveillance of Resistant Pathogens (ANSORP) Study. Clin. Infect. Dis. 28:1206-1211.

14. Sutcliff, J., A. Tait-Kamradt, and L. Wondrack. 1996. Streptococcus pneumoniae and Streptococcus pyogenes resistant to macrolides but sensitive to clindamycin: a common resistance pattern mediated by an efflux system. Antimicrob. Agents Chemother. 40:1817-1824.

15. Tait-Kamradt, A., J. Clancy, M. Cronan, F. Dib-Haji, L. Wondrack, W. Yuan, and J. Sutcliffe. 1997. mefE is necessary for the erythromycin-resistant M phenotype in Streptococcus pneumoniae. Antimicrob. Agents Chemother. 41:2251-2255.

15a.Tait-Kamradt, A., T. Davies, M. Cronan, M. R. Jacobs, P. C. Appelbaum, and J. Sutcliffe. 2000. Mutations in 23S rRNA and ribosomal protein L4 account for resistance in pneumococcal strains selected in vitro by macrolide passage. Antimicrob. Agents Chemother. 44:2118-2125.

16. Tarasi, A., Y. Chong, K. Lee, and A. Tomasz. 1997. Spread of the serotype $23 \mathrm{~F}$ multidrug-resistant Streptococcus pneumoniae clone to South Korea. Microb. Drug Resist. 3:105-109.

17. Yoshida, R., Y. Hirakata, M. Kaku, H. Takemura, H. Tanaka, K. Tomono, H Koga, S. Kohno, and S. Kamihira. 1997. Genetic relationship of penicillin resistant Streptococcus pneumoniae serotype 19B strains in Japan. Epidemiol. Infect. 118:105-110. 